\title{
Kinetics of Direct Reduction Titanomagnetite Concentrate Briquette Produced from Rossetta-Ilmenite via Hydrogen
}

\author{
Naglaa Ahmed El-Hussiny1, Atef El-Amir², Saied Thabet Abdel-Rahim³, Khaled El hossiny", \\ Mohamed El-Menshawi Hussein Shalabi ${ }^{*}$ \\ ${ }^{1}$ Central Metallurgical Research and Development Institute (CMRDI), Cairo, Egypt \\ ${ }^{2}$ Egyptian iron and Steel Company, Helwan, Egypt \\ ${ }^{3}$ Chemistry Department, Faculty of Science, Ain Shams University, Cairo, Egypt \\ ${ }^{4}$ Nuclear Materials Authority (NMA), Cairo, Egypt \\ Email: shalabimeh@hotmail.com, atef20109@yahoo.com, sayedth@hotmail.com, \\ hossiny.dr-khaledelhossany@hotmail.com, naglaaelhussiny@yahoo.com, shalabimeh@hotmail.com
}

Received 6 May 2014; revised 16 June 2014; accepted 26 July 2014

Copyright (C) 2014 by authors and OALib.

This work is licensed under the Creative Commons Attribution International License (CC BY). http://creativecommons.org/licenses/by/4.0/

(c) (i) Open Access

\begin{abstract}
Reduction kinetics of titanomagnetite concentrate briquettes produced from Rossetta-llmenite ore via $1.5 \mathrm{liter} / \mathrm{min}$ hydrogen flow rate were investigated at different temperatures ranging from $600^{\circ} \mathrm{C}$ to $950^{\circ} \mathrm{C}$. It was found that the best reduction properties were found at $950^{\circ} \mathrm{C}$, so the kinetic models shown by the briquettes at this temperature maybe: Diffusion control or Diffusion through ash layer (crank-cinslling-Broushten equation). And the apparent activation energy calculated for these models was 33.223 and $30.389 \mathrm{~kJ} / \mathrm{mole}$ respectively. Also the main crystalline phases of reduced briquettes at $950^{\circ} \mathrm{C}$ were metallic iron (syn. Fe), rutile (syn. $\mathrm{TiO}_{2}$ ) and some traces of magnetite $\left(\mathrm{Fe}_{3} \mathrm{O}_{4}\right)$.
\end{abstract}

Keywords

Titanomagnetite, Ilmenite Hydrogen, Reduction Kinetics

Subject Areas: Inorganic Chemistry, Physical Chemistry

\section{Introduction}

It is well known that there are many difficulties in utilizing the abundant and low-grade titanic minerals. As sources of high-grade titanic mineral decrease worldwide, more attention must be paid to processes involving

\footnotetext{
${ }^{*}$ Corresponding author.
}

How to cite this paper: El-Hussiny, N.A., El-Amir, A., Abdel-Rahim, S.Th., El hossiny, K. and Shalabi, M.E.H. (2014) Kinetics of Direct Reduction Titanomagnetite Concentrate Briquette Produced from Rossetta-Ilmenite via Hydrogen. Open Access $\mathrm{Li}$ brary Journal, 1: e662. http://dx.doi.org/10.4236/oalib.1100662 
low-grade minerals such as ilmenite and titaniferous magnetite. Titaniferous magnetite is one of the most abundant and widespread titanium-bearing minerals. It can be used for producing titanium metal and titanium dioxide. Due to the high content of impurities in these minerals, especially iron, it is necessary to upgrade them to obtain synthetic rutile and remove iron from it [1]. Titanium-containing magnetite ore (titanomagnetite ore or iron sand) is used as a source of iron in iron making. Reduction behaviour of titanomagnetite ore attracts attention from the viewpoint of its commercial processing and is extremely interesting from the viewpoint of the effect of the ore chemistry and morphology on reduction mechanisms and kinetics [2]. In the past decades, a number of studies have been conducted to improve the utilization of titaniferous ores, including smelting [3], direct acid leaching [4], selective chlorination [5] and reduction [6]. Among these, the direct reduced iron (DRI) process is supposed to be a more practical and effective way. In the industrial production, DRI-electric arc furnace (EAF) melting separation method has been proposed for refining both metallic iron and Ti slag from the titaniferous magnetite concentrate. In this method, the role of DRI process is to produce pre-reduction pellets (with the metallization degree $60 \%$ - 75\%) for EAF melting and reduction equipment mainly adopts the rotary-kiln [7]. However, the solid state carbothermic reduction in rotary-kiln is relatively slow with high-energy consumption and narrow operating temperature range [8] [9], which stimulates researches into gaseous reduction of titaniferous ores.

Vijay et al. [10] have investigated the reduction of Quilon ilmenite beach sand with hydrogen in a fluidized bed reactor and found that the reduction period could be divided into three distinct stages: initial slow induction stage, intermediate acceleratory stage and final slowing down stage. The results of Park and Ostrovski [11] have shown that the reduction of New Zealand TTM iron-sand in the fixed bed reactor by hydrogen gas was slower than that of hematite or magnetite iron ores. Wang et al. [12] have studied the hydrogen reduction kinetics of Bama ilmenite and considered that diffusion of hydrogen gas in the reduced layer was the rate controlling step.

Dang et al. [13] have investigated the reduction of titanomagnetite powder containing 56.9 mass\% of iron and 9.01 mass\% of $\mathrm{TiO}_{2}$ with $\mathrm{H}_{2}$-Ar gas mixtures in isothermal experiments using thermo-gravimetric analyzer (TGA). The reduction of titano-magnetite was proved to proceed via a dual reactions mechanism. The first reaction is reduction of titano-magnetite to wüstite and ilmenite and the second one is reduction of wüstite and ilmenite to iron and titanium-containing phase. It was found that the dual reactions occurred simultaneously during the reduction. The reduction kinetics of titano-magnetite was analyzed according to a dual reactions kinetic model and the results indicated that the gaseous species diffusion in product layer was the rate controlling step for the first reaction, and interfacial chemical reaction was that for the second reaction. The apparent activation energies were extracted to be $98 \mathrm{~kJ} / \mathrm{mol}$ and $115 \mathrm{~kJ} / \mathrm{mol}$ for the first and second reaction respectively.

The aim of this investigation is to obtain data on reduction behaviour of titanomagnetite briquettes that produced from the concentration process of Rossetta beach ilmenite ore which was provided by the black sands project of Nuclear Material Authority (NMA) via hydrogen gas at moderate temperature.

\section{Materials and Experiments}

\subsection{Materials}

The titanomagnetite concentrate (TMC) used in this study was obtained from Rossetta-Ilmenite ore that delivered from Nuclear Materials Authority (NMA). After drying and grinding, the particle size of concentrate was 5.03 up to $64.79 \mu \mathrm{m}$. While the chemical composition of titanomagnetite concentrate is listed in Table 1.

Phase characteristic of sample was investigated by XRD. X-ray diffraction (XRD, Bruker axs D8, Germany) with $\mathrm{Cu}-\mathrm{K}(\lambda=1.5406 \AA)$ radiation and secondary monochromator in the range $2 \theta$ from $20^{\circ}$ to $75^{\circ}$ was used to identify the formed phases. A Nikon Eclipse TS100 Optical Microscope (OM) with a Kodak Megaplus Camera in conjunction with Clemex Vision Professional Edition software was used for observation of the microstructure and image analysis.

The results of x-ray diffraction of the sample as shown in Figure 1, indicate that the main crystalline phases of concentrate are Ilmenite $\left(\mathrm{Fe}^{2+} \mathrm{TiO}_{3}\right)$ Magnetite $\left(\mathrm{Fe}_{3} \mathrm{O}_{4}\right)$, Hematite $\left(\mathrm{Fe}_{2} \mathrm{O}_{3}\right)$ and traces of Anatase $\left(\mathrm{TiO}_{2}\right)$.

\subsection{Experimental Work}

The titanomagnetite concentrate (TMC) was ground in a vibrating mill to a size less than 75 micrometers. The (TMC) powder ( $10 \mathrm{~g})$ was mixed with $2 \%$ molasses, then the mixture was subjected to briquetting process under different pressing load (varied from 75 to $275 \mathrm{MPa}$ ) to produce briquettes having the diameter of $12 \mathrm{~mm}$ and a 
Table 1. The chemical compositions of the titanomagnetite concentrate (TMC).

\begin{tabular}{ccc}
\hline Components & Percentage, \%. \\
\hline $\mathrm{Fe}$ & 52.71 \\
$\mathrm{FeO}$ & 23.22 \\
$\mathrm{SiO}_{2}$ & 4.3 \\
$\mathrm{CaO}$ & 1.05 \\
$\mathrm{MgO}$ & 1.17 \\
$\mathrm{Al}_{2} \mathrm{O}_{3}$ & 1.72 \\
$\mathrm{MnO}$ & 0.56 \\
$\mathrm{~S}$ & 0.04 \\
$\mathrm{P}_{2} \mathrm{O}_{5}$ & 0.08 \\
$\mathrm{TiO}_{2}$ & 18.06 \\
\hline
\end{tabular}

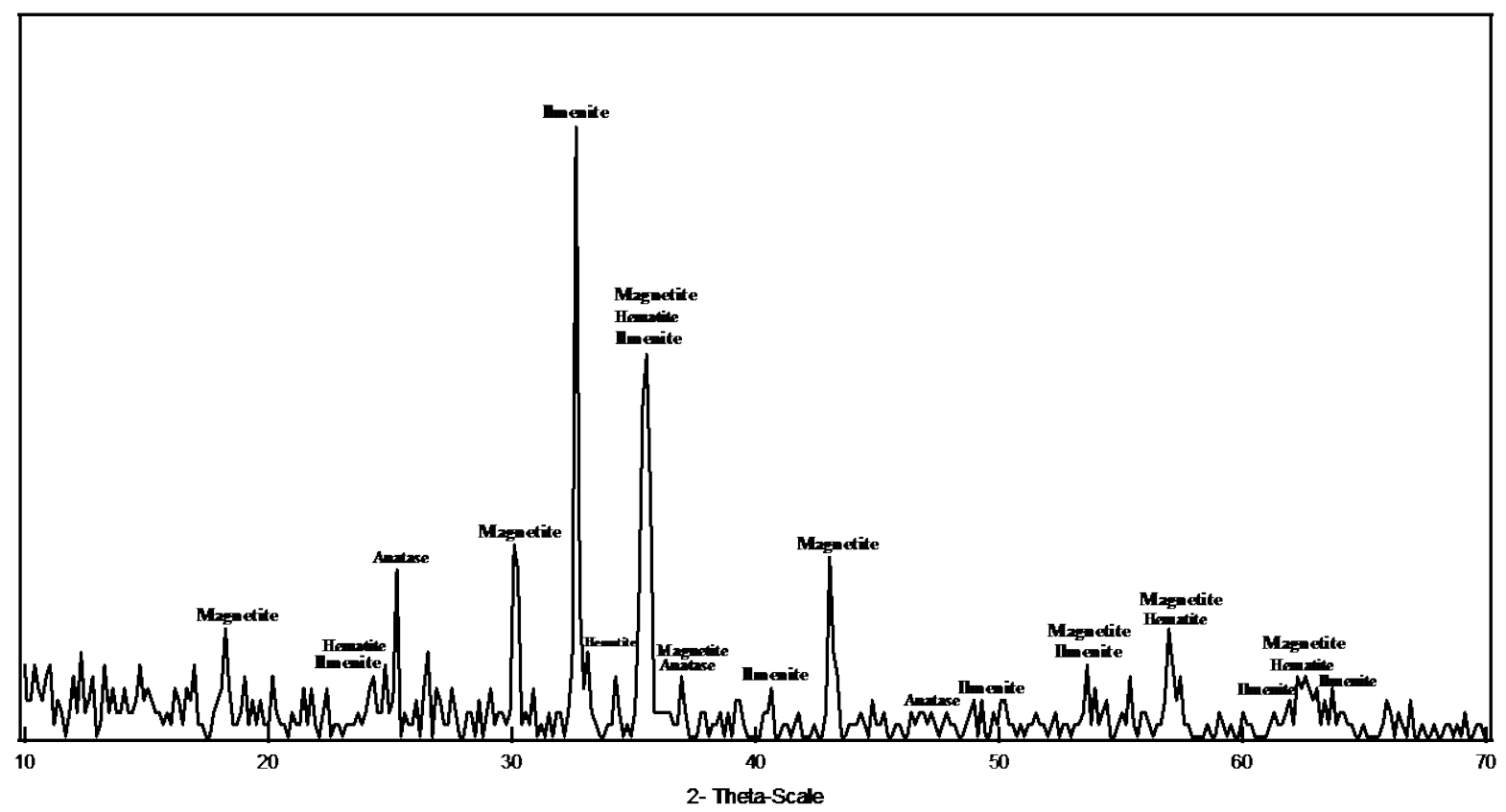

Figure 1. XRD for original sample.

height of 25 mm using MEGA.KSC-10 hydraulic press.

\subsection{Characterization}

The produced briquettes were characterized from its mechanical properties point of view. The most important mechanical properties of the produced briquette (green briquette or dry in atmospheric conditions for 7 days), are its drop damage resistance and compressive strength. The drop damage resistance was measured by dropping ten briquettes individually from a height of $30 \mathrm{~cm}$ onto a steel plate until its breakage. The mean value of the tested briquettes gives their average dropping damage resistance [14]-[16].

On the other hand the compressive strength of the produced briquettes was measured via subjecting at least 10 briquettes for compression between parallel steel plates up to their breakage. This test is carried out on a platform balance with weight indication by means of a pointer. The briquette to be tested is placed on the lower steel 
plate of the balance and is gradually compressed with a steel plate while the pointer position is observed. The briquette breakage is indicated by the jumping back of the pointer. The maximum weight load observed corresponds to the compressive strength of the briquette. The mean value for the tested briquettes gives their compressive strength. The observed load corresponds to the compressive strength measured in MPa for briquette [14] [17].

The reduction of the produced briquette was done on a thermo gravimetric apparatus is done by hydrogen at different flow rate $1 / \mathrm{min}$, constant time of reduction and different temperatures. A schematic diagram of thermo gravimetric apparatus as shown in Figure 2 is similar to that used by El-Hussiny and Shalabi [18], which consisted of a vertical furnace, electronic balance for monitoring the weight change of reacting sample and temperature controller. The sample was placed in an alumina crucible which was suspended under the electronic balance by $\mathrm{Ni}-\mathrm{Cr}$ wire. The furnace temperature was raised to the required temperature and maintained constant to $\pm 5^{\circ} \mathrm{C}$. Then samples were placed in hot zone. All reduction experiments were done in nitrogen atmosphere $(0.5$ $1 / \mathrm{min}$ ). The weight of the sample was continuously recorded every $5 \mathrm{~min}$. At the end of the run, the samples were withdrawn from the furnace and put in desiccators.

The percentage of reduction was calculated according to the following equations:

$$
\text { Percent of reduction }=\frac{(W 0-W 1) \times 100 \times 16}{\text { Oxygen }(\text { mass }) \times 28}
$$

where:

$W 0$ : is the initial mass of sample after removal of moisture;

$W 1$ : is the mass of sample after each time $t$.

Oxygen (mass) indicates the mass of oxygen percent in the titanomagnetite concentrate (TMC) in form FeO $\& \mathrm{Fe}_{2} \mathrm{O}_{3}$ and oxygen loss due to convert them into iron (Fe).

\section{Results and Discussions}

\subsection{Effect of Pressing Load on the Quality of the Produced Briquettes}

The drop damage resistance and compressive strength of the produced briquettes with respect to different pressing load and at constant amount of molasses (2\%) are shown in Figures 3-6. From these figures, it was found that as the pressing load increased from 87 to $261 \mathrm{MPa}$. The drop damage resistance and the compressive strength for both green and dried briquettes increased and reached to its maximum values at $260.0849 \mathrm{MPa}$. This could be attributed to the fact that increasing pressing load leads to increase the number of contact points between particles and subsequently the Vander Waals force increased [19]-[21].

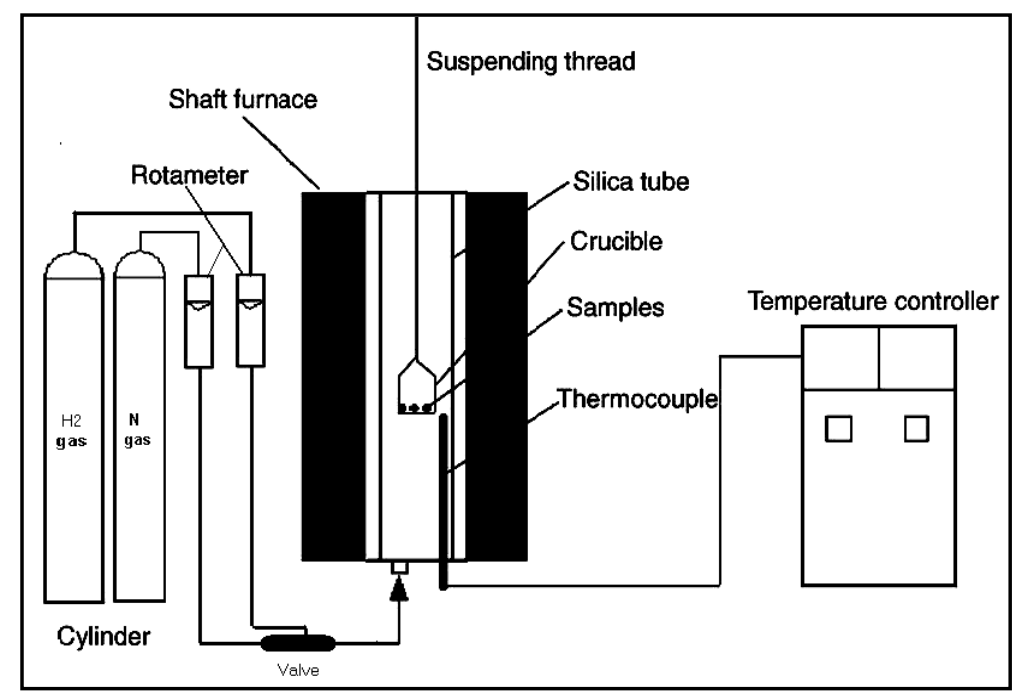

Figure 2. Schematic diagram of the apparatus. 


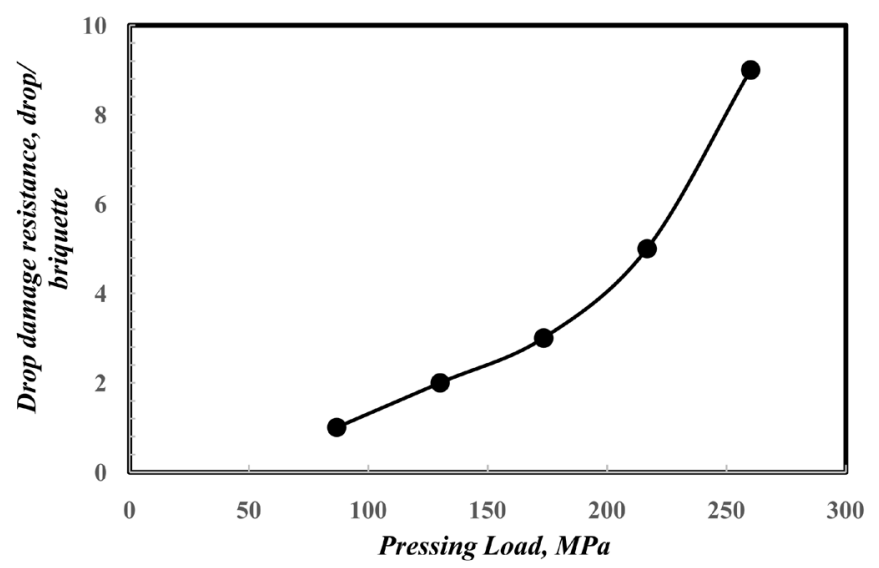

Figure 3. Effect of pressing pressure on the drop damage resistance of green briquettes pressed at constant binding materials percent $2 \%$ molasses.

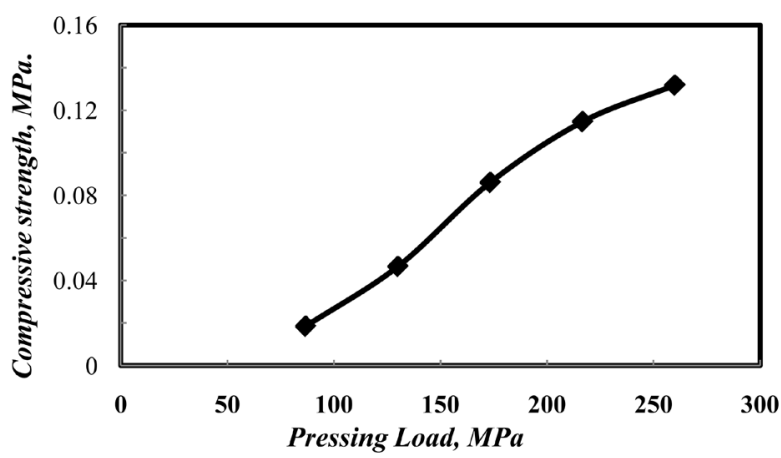

Figure 4. Effect of pressing pressure on the compressive strength of green briquettes pressed at constant binding materials percent $2 \%$ molasses.

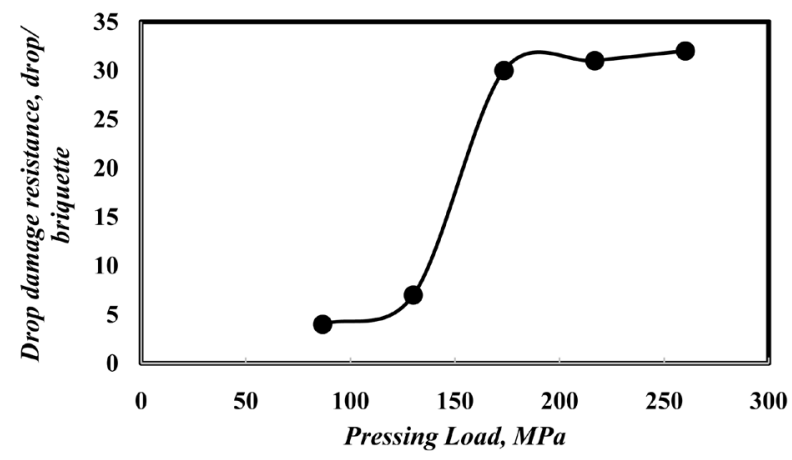

Figure 5. Effect of pressing pressure on the drop damage resistance of dry briquettes pressed at constant binding materials percent $2 \%$ molasses.

\subsection{Effect of Hydrogen Flow Rate on the Reducibility of Iron Oxides Content of Titanomagnetite Concentrate Briquettes at $900^{\circ} \mathrm{C}$}

Figure 7 illustrates the relation between the reduction degree and time of reduction at different hydrogen flow rate when the reduction were done at constant temperature $\left(900^{\circ} \mathrm{C}\right)$, the weight of the sample was constant and this sample was pressed at 260.0849 MPa. It is clear that as the flow rate of hydrogen increased the reduction percentage increased. This may be due to the fact that increase of flow rate leads to increasing the number of hydrogen moles in the bulk phase, which in turn leads to the raise of hydrogen adsorption. In this way, the rate of reaction increased [22] or the increase of flow rate increased and the gas diffusion across the boundary layer 


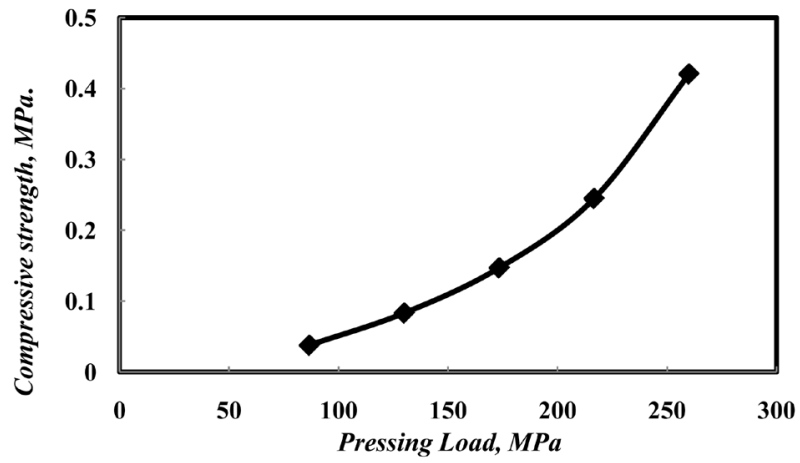

Figure 6. Effect of pressing pressure on the compressive strength of dry briquettes pressed at constant binding materials percent $2 \%$ molasses.

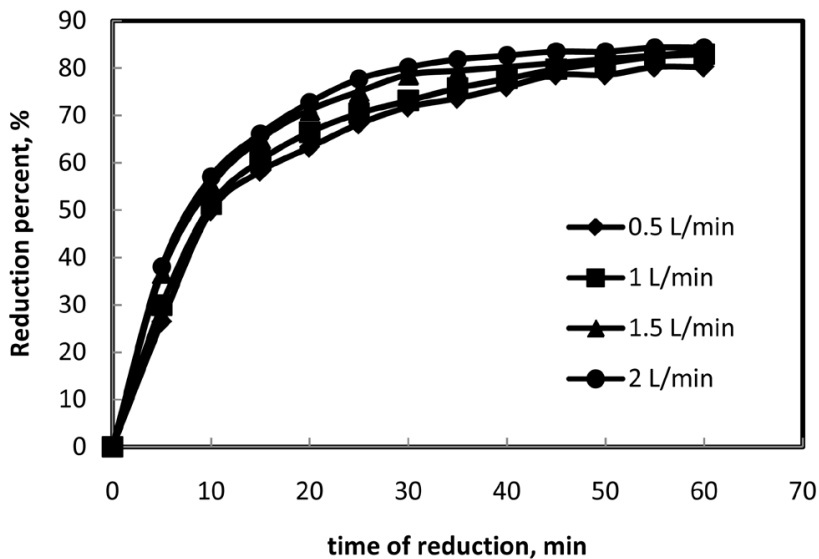

Figure 7. Effect of reduction time on the percent of reduction by hydrogen of briquettes (titanomagnetite concentrate $+2 \%$ molasses) pressed at $260.09 \mathrm{MPa}$ at different hydrogen flow rates and $900^{\circ} \mathrm{C}$.

subsequently the ion reduction increased [23] [24]. Also may be the higher flow rate prevailing in the reaction zone which enhances the rate of hydrogen absorption and subsequently the rate of chemical reaction steps increased [25] [26].

\subsection{Effect of Reduction Temperatures on the Reducibility of Iron Oxides Content of Titanomagnetite Concentrate Briquettes}

The reduction was carried out at different temperatures ranging from $600^{\circ} \mathrm{C}$ to $950^{\circ} \mathrm{C}$, where the briquette pressed at $260.09 \mathrm{MPa}$ and the hydrogen flow rate was $1.5 \mathrm{liter} / \mathrm{min}$. The results of the investigation are shown on Figure 8, where it is clear that the increase of temperature favors the reduction rate. At high reduction temperature, with increasing temperature, the oxygen removal increased. The analyze of the curves relating the reduction percentage and time of reduction show that each curve has 3 different slopes indicating 3 different values of reduction rates. The first value is high, while the second is somewhat slower and the third is the slowest one. The increase of reduction percentage with temperature could be due to increase number of reacting moles having excess energy which leads to the increase of adsorption rate. Also increasing temperature leads to increase the rate of mass transfer of the diffusion and rate of chemical reaction [23] [25].

\subsection{Kinetics of the Reduction Process}

Kinetic studies for estimation of apparent activation energies were carried out for titanomagnetite concentrate produced from Rosetta illmenite ore briquettes at five different temperatures of $600^{\circ} \mathrm{C}, 700^{\circ} \mathrm{C}, 800^{\circ} \mathrm{C}, 900^{\circ} \mathrm{C}$ and $950^{\circ} \mathrm{C}$ for different time intervals in the range of 0 - 60 minutes. 
1) By using diffusion process controls Equation [27]

$$
1-2 / 3 f-(1-f)^{(2 / 3)}=k t
$$

where $f$ is fractional reduction, $t$ is time of reduction, $k$ is the rate constant.

Figure 9 illustrates the relation between $1-2 / 3 f-(1-f)^{(2 / 3)}=k t$ against time of reduction for different reduction temperature. From which it is clear that the relationship is represented by straight line. The natural logarithms were used according to the Arrhenius equation to calculate the activation energies of reduction reaction. The results were illustrated on Figures 12 from which it is clear that briquette has activation energy $=33.223$ $\mathrm{kJ} / \mathrm{mole}$.

Or

2) When using Diffusion through ash layer (crank-cinslling-Broushten equation) [28]

$$
\left(1-3(1-f)^{2 / 3}+2(1-f)\right)=k t
$$

Figure 10 illustrates the relation between $\left(1-3(1-f)^{2 / 3}+2(1-f)\right)=k t$ against time of reduction for different reduction temperature. From which it is clear that the relationship is represented by straight line.

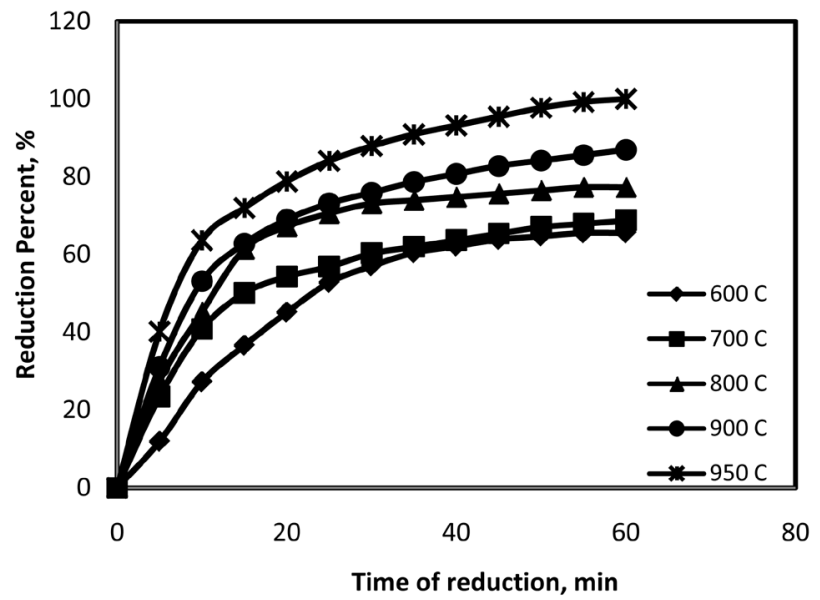

Figure 8. Effect of reduction time on the percent of reduction by hydrogen of briquettes (titanomagnetite concentrate $+2 \%$ molasses) pressed at $260.09 \mathrm{MPa}$ at different temperatures.

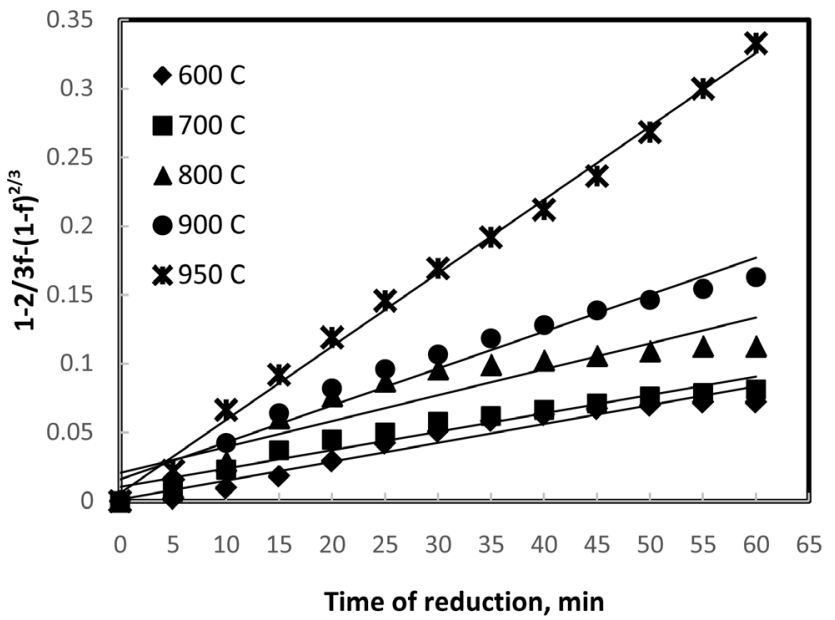

Figure 9. The relationship between time of reduction and $1-2 / 3 f-(1-f)^{(2 / 3)}$ at different temperature. 
The natural logarithms were used according to the Arrhenius equation to calculate the activation energies of reduction reaction by using the calculated rate constant $k$.

$$
\begin{gathered}
k=k_{0} \exp \left(-\frac{E}{R T}\right) \\
\ln k=\ln k_{0}-\frac{E}{R T}
\end{gathered}
$$

where $k_{0}$ is the coefficient; $E$ is the apparent reduction activation energy; $R$ is the universal gas constant [8.314 $\times$ $\left.10^{-3} \mathrm{~kJ} /(\mathrm{mol} \cdot \mathrm{K})\right]$; $\mathrm{T}$ is the absolute temperature. The relationships between the natural logarithm of reduction rate constant and the reciprocal of absolute temperature for titanomagnetite concentrate produced from Rosetta illmenite ore briquettes are shown in Figure 11 and Figure 12, from which it is clear that briquette has activation energy $=33.223 \mathrm{~kJ} /$ mole for model $1-2 / 3 f-(1-f)^{(2 / 3)}=k t$ while the activation energy $=30.389 \mathrm{~kJ} / \mathrm{mole}$ for model $\left(1-3(1-f)^{2 / 3}+2(1-f)\right)$ respectively.

\subsection{X-Ray Analyses of the Reduced Briquette}

X-ray analyses of the sample reduced at $950^{\circ} \mathrm{C}$ shows that the present phases are metallic iron (syn. $\mathrm{Fe}$ ), rutile (syn. $\mathrm{TiO}_{2}$ ) and some traces of magnetite $\left(\mathrm{Fe}_{3} \mathrm{O}_{4}\right)$ as shown in Figure 13.

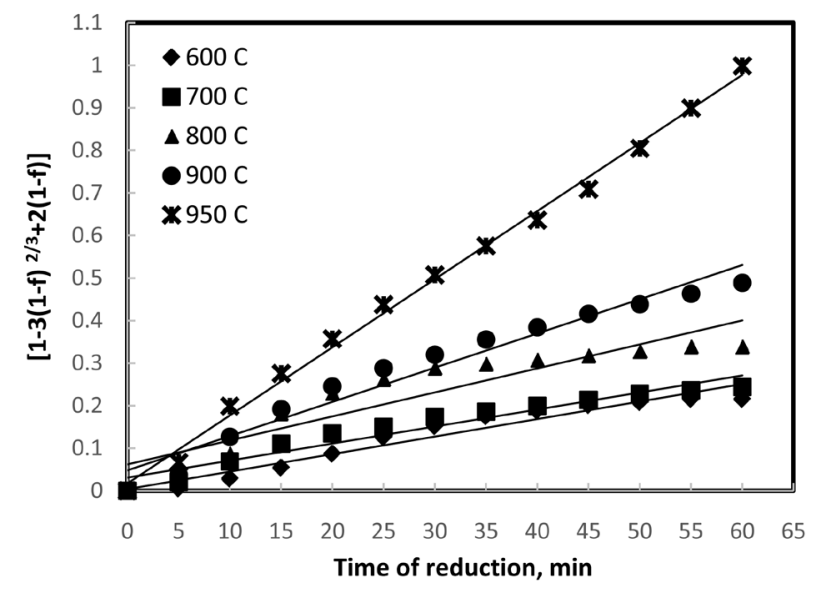

Figure 10. The relationship between time of reduction and $\left(1-3(1-f)^{2 / 3}+2(1-f)\right)$ at different temperature.

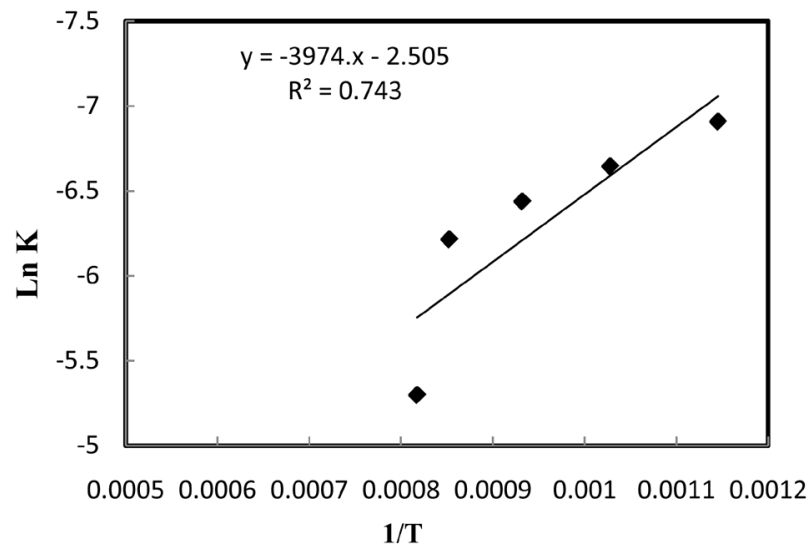

Figure 11. The relation between the reciprocal of absolute temperature $1 / T$ and $\ln K$ (Arrhenius plot for reduction reaction) for model $1-2 / 3 f-(1-f)^{(2 / 3)}$. 


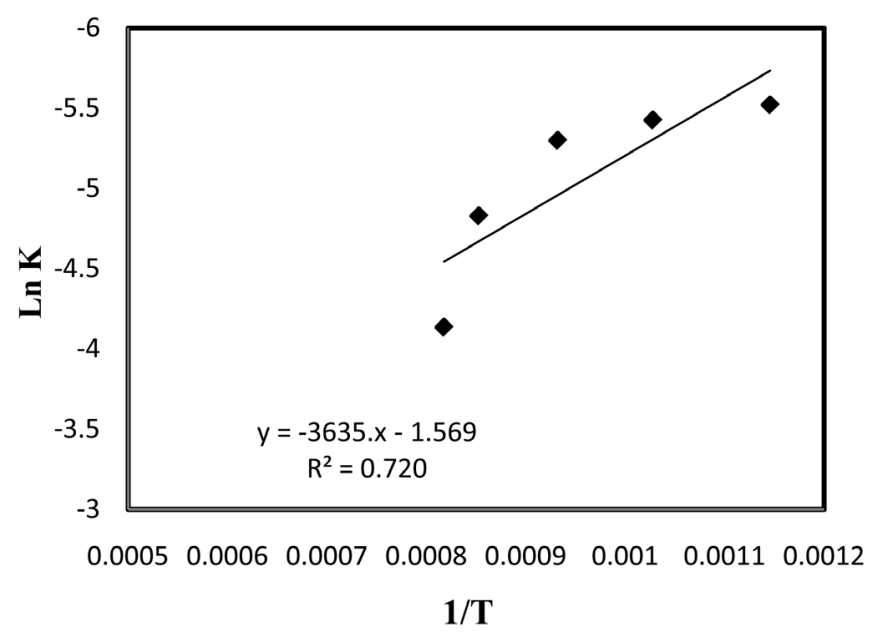

Figure 12. The relation between the reciprocal of absolute temperature $1 / T$ and $\ln K$ (Arrhenius plot for reduction reaction) for model $\left(1-3(1-f)^{2 / 3}+2(1-f)\right.$ ).

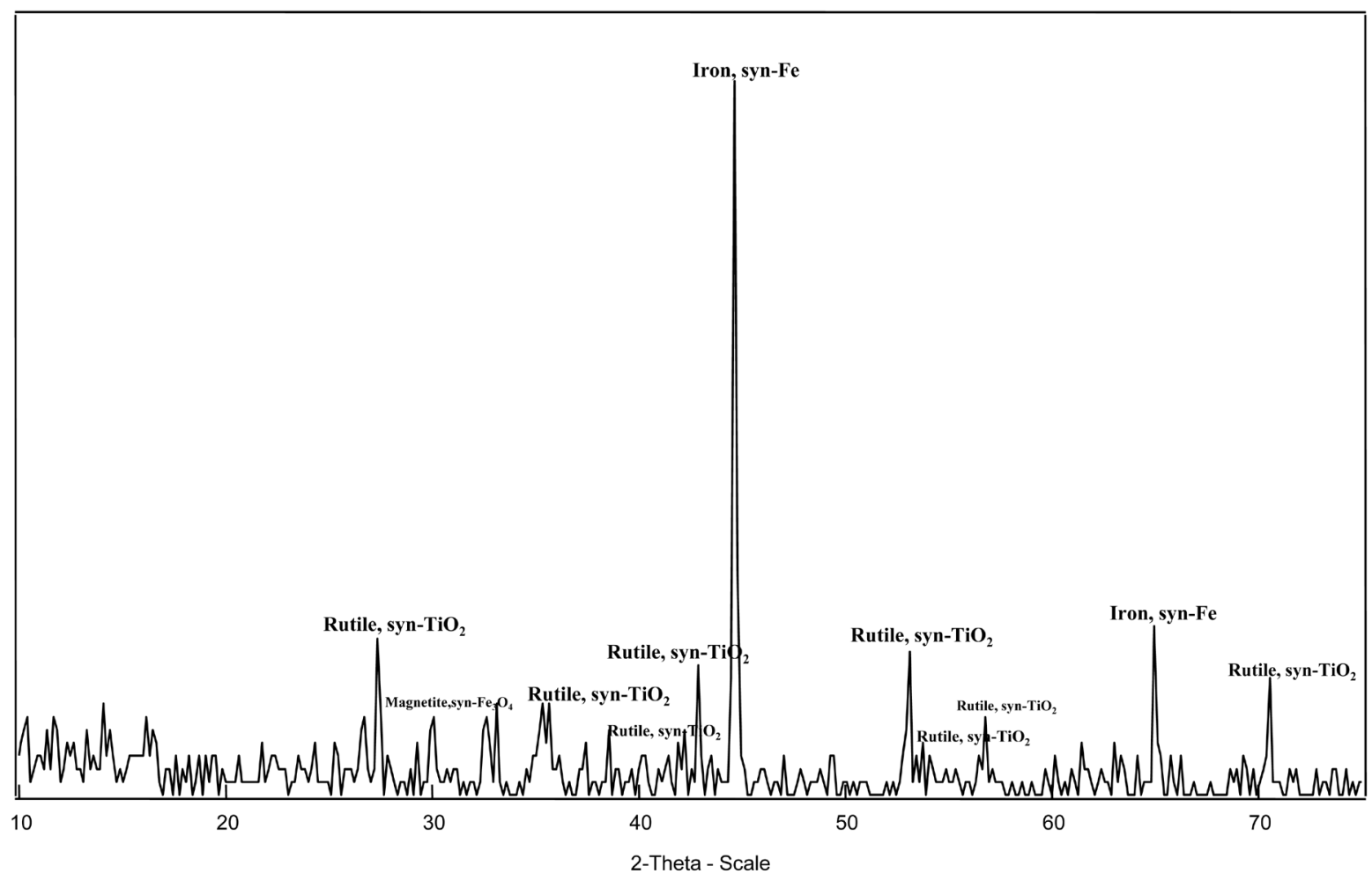

Figure 13. XRD analysis of reduced titanomagnetite concentrate briquettes at $950^{\circ} \mathrm{C}$.

\subsection{Microscopic Analyses of the Reduced Titano Magnetite}

Figure 14 illustrated the microstructure of reduced titanomagnetite at $950^{\circ} \mathrm{C}$ by hydrogen from which it is clear that the main phase (white color) is metallic iron.

\section{Conclusions}

1) The compressive strength and the drop damage resistances of titanomagnetite concentrate briquettes increased with increasing the pressing pressure up to $260.09 \mathrm{MPa}$. at $2 \%$ molasses. 


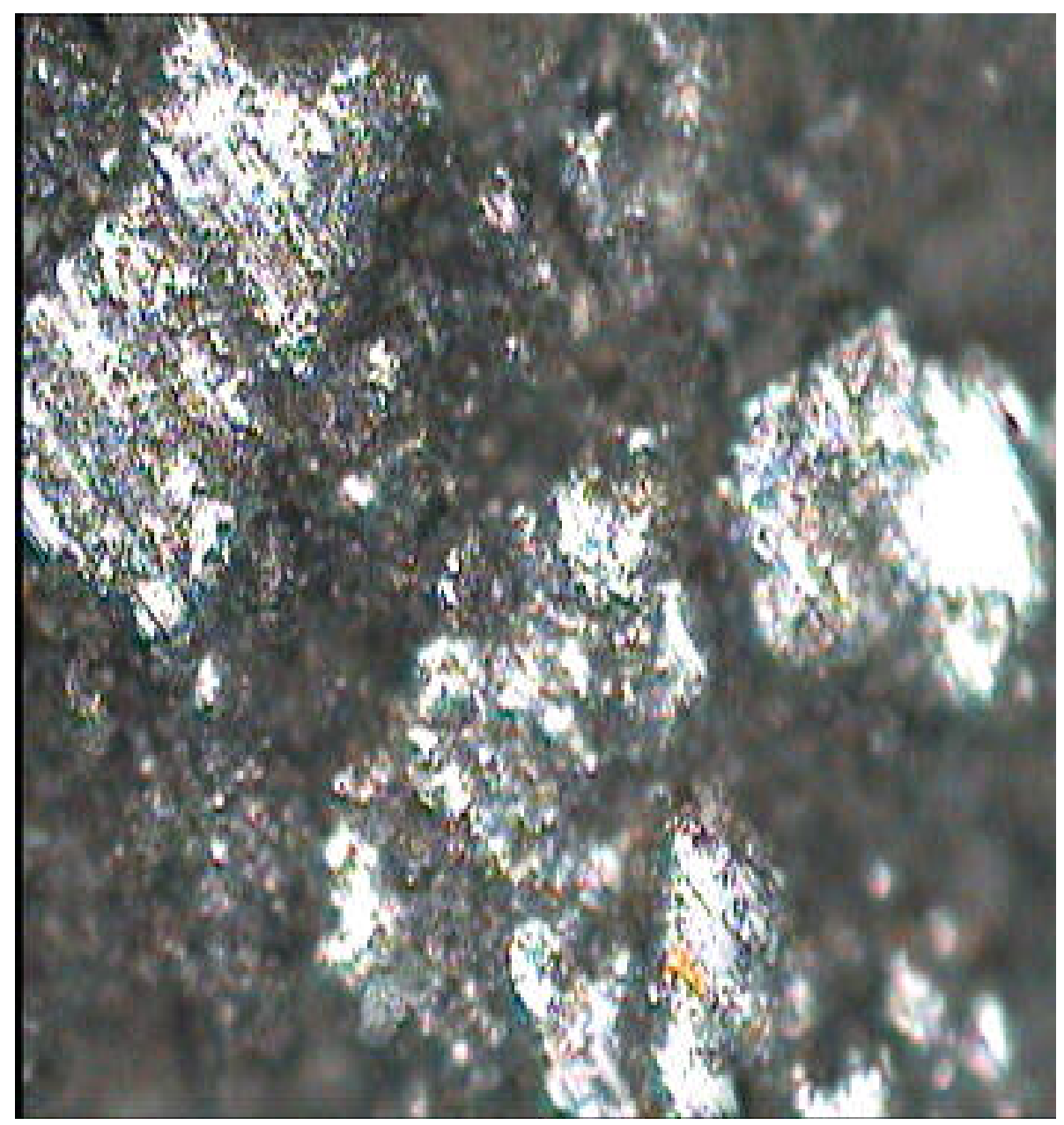

Figure 14. Microstructure of reduced titanomagnitite at $950^{\circ} \mathrm{C}$ by hydrogen.

2) The reduction rates increased with increasing temperature of the reduction from $600^{\circ} \mathrm{C}$ up to $950^{\circ} \mathrm{C}$.

3) The reduction rate increased with the increase of hydrogen flow rate at constant temperature.

4) The diffusion processes through the produced briquettes is the reduction control step and the briquettes have activation energy $=33.223 \mathrm{~kJ} /$ mole for model $1-2 / 3 f-(1-f)^{(2 / 3)}=k t$, while the activation energy $=$ $30.389 \mathrm{~kJ} /$ mole for model $\left(1-3(1-f)^{2 / 3}+2(1-f)\right)$ respectively.

\section{References}

[1] Rhee, K.I. and Sohn, H.Y. (1990) The Selective Carbo-Chlorination of Iron from Titaniferous Magnetite Ore in a Fluidized Bed. Metallurgical Transactions B, 21B, 341- 347.

[2] Longbottom, R.J., Ostrovski, O. and Park, E. (2006) Formation of Cementite from Titanomagnetite Ore. ISIJ International, 46, 641-646. http://dx.doi.org/10.2355/isijinternational.46.641

[3] Pistorius, P.C. and Coetzee, C. (2003) Physicochemical Aspects of Titanium Slag Production and Solidification. Metallurgical and Materials Transactions B, 34, 581-588. http://dx.doi.org/10.1007/s11663-003-0027-8

[4] El-Hazek, N., Lasheen, T.A., El-Sheikh, R. and Zaki, S.A. (2007) Hydrometallurgical Criteria for $\mathrm{TiO}_{2} \mathrm{Leaching}_{\text {from }}$ Rosetta Ilmenite by Hydrochloric Acid. Hydrometallurgy, 87, 45-50. http://dx.doi.org/10.1016/j.hydromet.2007.01.003

[5] Andrew, A., Li, Y., Zhang, G.Q. and Oleg, O. (2011) Chlorination of Reduced Ilmenite Concentrates and Synthetic Rutile. International Journal of Mineral Processing, 100, 166-171.

[6] Kucukkaragoz, C.S. and Eric, R.H. (2006) Solid State Reduction of a Natural Ilmenite. Minerals Engineering, 19, 334337. http://dx.doi.org/10.1016/j.mineng.2005.09.015

[7] Sun, H.Y., Wang, J.S., Dong, X.J. and Xue, Q.G. (2012) A Literature Review of Titanium Slag Metallurgical 
Processes. Minerals Engineering, 17, 49-56.

[8] Dancy, T.E. (1993) The Development of Direct Reduction Processes. Scandinavian Journal of Metallurgy, 22, 100108.

[9] Pelton, A.D. and Bale, C.W. (1999) Direct Reduced Iron: Technology and Economics of Production and Use. Iron \& Steel Society, Warrendale.

[10] Vijay, P.L., Venugopalan, R. and Sathiyamoorthy, D. (1996) Preoxidation and Hydrogen Reduction of Ilmenite in a Fiuidized Bed Reactor. Metallurgical and Materials Transactions B, 27, 731-738. http://dx.doi.org/10.1007/BF02915601

[11] Park, E. and Ostrovski, O. (2004) Reduction of Titania-Ferrous Ore by Hydrogen. ISIJ International, 44, 990-1005. http://dx.doi.org/10.2355/isijinternational.44.999

[12] Wang, Y.M., Yuan, Z.F., Matsuura, H. and Tsukihashi, F. (2009) Reduction Extraction Kinetics of Titania and Iron from an Ilmenite by $\mathrm{H}_{2}$-Ar Gas Mixtures. ISIJ International, 49, 164-170. http://dx.doi.org/10.2355/isijinternational.49.164

[13] Dang, J., Hu, X., Zhang, G., Hou, X., Yang, X. and Chou, K. (2013) Kinetics of Reduction of Titano-Magnetite Powder by $\mathrm{H}_{2}$. High Temperature Materials and Processes, 32, 229-236.

[14] Mayer, K. (1980) Pelletization of Iron Ores. Springer-Verlag Berlin Heidelberg, Berlin.

[15] Forsmo, S.P.E., Apelqvist, A.J., Björkman, B.M.T. and Samskog, P.O. (2006) Binding Mechanisms in Wet Iron Ore Green Pellets with a Bentonite Binder. Powder Technology, 169, 147-158. http://dx.doi.org/10.1016/j.powtec.2006.08.008

[16] Forsmo, S.P.E., Samskog, P.O. and Björkman, B.M.T. (2008) A Study on Plasticity and Compression Strength in Wet Iron Ore Green Pellets Related to Real Process Variations in Raw Material Fineness. Powder Technology, 181, 321330. http://dx.doi.org/10.1016/j.powtec.2007.05.023

[17] Annual Book of ASTM Standards, ASTM E 382. Standard Test Method for Determination of Crushing Strength of Iron Ore Pellets.

[18] El-Hussiny, N.A. and Shalabi, M.E.H. (2012) Studying the Pelletization of Rosseta Ilmenite Concentrate with Coke Breeze Using Molasses and Reduction Kinetics of Produced Pellets at 800-1150 ${ }^{\circ}$ C. Science of Sintering, 44, 113-126. http://dx.doi.org/10.2298/SOS1201113E

[19] Mohamed, F.M., Ahmed, Y.M.Z. and Shalabi, M.E.H. (2004) Briquetting of Waste Manganese Ore Sinter Fine Using Different Binding Materials. Environmental Issues and Waste Management in Energy and Mineral Production SWEMP 2004, 567-573.

[20] Mangena, S.J. and Cann, V.M. (2007) Binderless Briquetting of Some Selected South African Prime Coking, Blend Coking and Weathered Bituminous Coals and the Effect of Coal Properties on Binderless Briquetting. International Journal of Coal Geology, 71, 303-312. http://dx.doi.org/10.1016/j.coal.2006.11.001

[21] Ingles, O.G. (1962) Microstructure in Binderless Briquetting. Agglomeration. Knepper, W.A., Ed., Interscience Publishers, New York, 29-53.

[22] Shalabi, M.E. (1973) Kinetic Reduction of El-Baharia Iron Ore and Its Sinter in Static Bed by Hydrogen. El-Tabbin: M.Sc. Theses, Metallurgical Institute for Higher Studies, Cairo.

[23] Sayed, S.A., Khalifa, G.M., El-Faramawy, E.S.R. and Shalabi, M.E.H. (2002) Kinetic Reduction of Low Manganes Iron Ore by Hydrogen. Egyptian Journal of Chemistry, 45, 47-66.

[24] El-Gawad, H.H.A., Ahmed, M.M., El-Hussiny, N.A. and Shalabi, M.E.H. (2014) Kinetics of Reduction of Low Grade SinaiManganese Ore Via Hydrogen at 800-950 C. Open Access Library Journal, 1, e427.

[25] Sayed, S.A., Khalifa, M.G., El-Faramawy, E.S.R. and Shalabi, M.E.H. (2001) Reductions Kinetic of El-Baharia Iron Ore in a Static Bed. Gospodarka Surowcami Mineranymi, 17, 241-245. (VII International Mineral Processingn Conference, Szczyrk, 17-19 September 2001)

[26] El-Gawad, H.H.A., El-Hussiny, N.A., Wassf, M.A., Kalifa, M.G., Iskander, B.A. and Shalabi, M.E.H. (2009) Briquetting of Rosetta Ilmenite Ore with Different Organic Binder and Its Reduction in Hydrogen in the Temperature Range of $800-1200^{\circ} \mathrm{C}$, Górnictwo i Geoinżynieria, 33, 25-40.

[27] Wang, Y. and Yuan, Z. (2006) Reductive Kinetics of the Reaction between a Natural Ilmenite and Carbon. International Journal of Mineral Processing, 81, 133-140. http://dx.doi.org/10.1016/j.minpro.2006.07.010

[28] Geiss, E.A. (1963) Equations and Tables for Analyzing Solid-State Reaction Kinetics. Journal of the American Ceramic Society, 46, 374-376. http://dx.doi.org/10.1111/j.1151-2916.1963.tb11754.x 